\title{
Debates em Educaçâo
}

\section{EDITORIAL, VOL. 5, N. 9, 2013}

O primeiro número, deste ano de 2013, da Revista - Debates em Educação, do Programa de Pós-Graduação em Educação da Universidade Federal de Alagoas, conta com trabalhos nacionais e internacionais que abordam temáticas diversas, resultantes de pesquisas no campo da Educação, envolvendo especialmente as políticas educacionais, a formação docente, as práticas socioculturais escolares e os vínculos históricos e sociais da prática docente. Tais pesquisas, de absoluta atualidade, revelam o trabalho criterioso e exaustivo dos estudiosos sobre temáticas que são, na verdade, espaços de luta de cada dia por uma educação de qualidade.

O debate permanece aberto e esperamos contar com novas contribuições para as próximas edições.

O primeiro artigo, de Giovanna Del Gobbo, da Università Degli Studi di Firenze (UNIFI/IT), intitulado "Novos olhares para novos pertencimentos: museus e competências transculturais" destaca a importância dos museus como um instrumento de mediação em sociedades que visam o diálogo entre diferentes identidades sociais e culturais. Segundo a autora, os museus são instrumentos pedagógicos de mediação e de intercâmbio que favorecem a construção de diferentes saberes culturais, favorecendo a construção de comunidades de aceitação das diferenças em direção a uma transculturalidade mundial.

O artigo intitulado "Dificuldades de Aprendizagem e insucesso escolar: uma cooperação internacional entre Itália e Brasil" de Cristina Coggi e Paola Ricchiardi, ambas da Università Degli Studi di Torino (UNITO) da Itália, apresentam o resultado de uma exaustiva pesquisa, fruto de um intercâmbio entre Brasil e Itália, sobre o insucesso escolar nos contextos italiano e brasileiro. As pesquisadoras destacam o 


\section{Debates em Educação}

papel do programa Fênix que tem por objetivo minimizar, com sucesso significativo, as dificuldades de aprendizagem identificadas nas crianças desses dois contextos.

O artigo intitulado "Questões sobre a formação de professores: profissionalização, formação e feminização/femilização" dos/as autores/as José Batista Neto e Eleta de Carvalho Freire da Universidade Federal de Pernambuco (UFPE), discute a feminização/femilização do trabalho docente e os vínculos entre a profissão e a formação de professores/as. O trabalho parte de uma perspectiva histórica até chegar aos processos de feminização/Femilização da profissão e seu papel na constituição de uma identidade docente.

Em relação à temática formação de professores, a autora Inalda Maria dos Santos, da Universidade Federal de Alagoas (UFAL), em seu artigo intitulado "A formação de professores e o curso de Pedagogia", aborda a formação de professores nos cursos de Pedagogia, destacando-os como espaço privilegiado para a qualificação de docentes, em particular para atuarem nas escolas públicas brasileiras. A autora pontua alguns dispositivos legais que, apesar de ainda insuficientes, têm favorecido o processo de qualificação e valorização da profissão no Brasil.

Seguindo essa temática, Lourdes Maria Bragagnolo Frison, da Universidade Federal de Pelotas (UFPel), destaca o papel do programa PIBID do Curso de Pedagogia da UFPel, junto às alunas do curso. Segundo a autora, o PIBID tem se revelado importante na constituição de docentes mais conectados à realidade educacional das escolas, favorecendo seu desempenho profissional futuro, especialmente no que se refere à alfabetização de crianças.

As autoras Bruna Pereira Alves Fiorin, Liliana Soares Ferreira e Maria Cecília Martins Manckel, da Universidade Federal de Santa Maria (UFSM), discutem, no artigo intitulado "A Lei 9394/96 como política educacional e o trabalho dos professores", as concepções que os docentes têm sobre o seu trabalho, buscando estabelecer pontos de contato com a LDB 9394/96. O tema é discutido a partir de resultados de uma pesquisa, que revelam que os professores tiveram dificuldades em descrever qual seria 


\section{Debates em Educação}

seu trabalho de fato, destacando que a LDB também não contribui para uma definição mais acurada da profissão.

Finalizamos com a pesquisa das autoras Roseana Maria de Amorim, Elizabete Amorim de Almeida Melo e Lílian Barbara Cavalcanti Cardoso, da Universidade Federal de Alagoas (UFAL), apresentada no artigo intitulado "A Universidade Federal de Alagoas na década de 1970: que profissionais se queria formar?". As autoras analisam os planos de ensino dos professores atuantes nos anos 70 na UFAL, com foco nos cursos de Ciências Humanas, visando identificar suas práticas curriculares. Para tanto, realizam uma contextualização histórica do período, relacionando os enfoques curriculares à tendência política dominante na época.

Desejamos uma boa leitura.

Laura Cristina Vieira Pizzi

Nadja Naira Ribeiro 